\title{
Rethinking course structure: increased participation and persistence in introductory post-secondary mathematics courses
}

\author{
Darja Barr ${ }^{*}$ (D) and Lindsay Wessel
}

\author{
*Correspondence: \\ Darja.Barr@umanitoba.ca \\ University of Manitoba \\ Winnipeg, Canada
}

\begin{abstract}
High failure and withdrawal rates in introductory post-secondary mathematics courses are a problem locally, nationally, and internationally. This leads to first-year mathematics courses creating a closed door, or a barrier, to further study of mathematics, of STEM disciplines, and in University as a whole. In this article, the authors describe the implementation of a modified course structure in a first-year undergraduate mathematics course. The new structure makes use of a combination of mastery learning strategies together with the beneficial effects of small class sizes to address the issues of historically high failure and withdrawal rates and low grade-point averages. Results show that careful planning of the structure of a course can have a positive effect on student success, and thus on attitude towards mathematics.
\end{abstract}

Keywords: Undergraduate mathematics, Failure and withdrawal rates, Course structure, Large classes, Mastery learning, Student success

\section{Introduction}

In recent years, there has been growing concern regarding the success of students in post-secondary mathematics courses $[17,33]$, and in fact some authors claim that future success in college and completion of a university degree can be affected by students' success in a first-year mathematics course [26,32]. Many large universities, including the one in this study, require students complete a math credit in order to qualify for graduation, regardless of the program they are enrolled in. Thus, success in a first-year math course plays a major role in students' overall university success.

The aforementioned authors believe that in order for individuals to be competitive in the workforce and for our society to be competitive in the world markets, our citizens need to be educated beyond the basic skill set. They must be able to understand and use advanced mathematical skills such as those gained in first-year mathematics courses and beyond. Therefore, it is critical that first-year mathematics courses become a "pump" rather than a "filter," or a "door" rather than a "barrier" [35]. However, the lack of participation and persistence in undergraduate mathematics within and after students' first-year course(s) is painting a bleak picture, one in which the revised course structure in this study attempts to address. By increasing students' success in the first-year

(c) The Author(s) 2017. This article is distributed under the terms of the Creative Commons Attribution 4.0 International License (http://creativecommons.org/licenses/by/4.0/), which permits unrestricted use, distribution, and reproduction in any medium provided you give appropriate credit to the original author(s) and the source, provide a link to the Creative Commons license, and indicate if changes were made. 
mathematics course of interest in this paper, it is the hope of the instructors that students participating in this course will persist to complete a degree of their choice, or perhaps even been encouraged to specialize in a STEM or mathematics focused program.

\section{Historical background}

As society has changed, post-secondary education has become available not only to the social elite, but to the masses $[17,36,38]$, and increasing enrollments in undergraduate mathematics courses would suggest comparative increases in the numbers of students majoring in mathematics, but this is not the case. The book $A$ Challenge of Numbers (1990) outlines historical trends and statistics in mathematics programs. The authors, Madison and Hart, describe the 'boom' in the numbers of mathematics bachelor degrees and mathematics enrollments after the launch of Sputnik in 1957 (pp. 2; see also [16]). Madison and Hart [24] note a "disparate trend" between undergraduate mathematics enrollments, which have been increasing steadily since the 1950s, and the number of mathematics majors, because most of the enrollment increase is happening at the remedial levels (pp. 36; see also [29]).

Data from the Office of Institutional Analysis (2013) show that undergraduate mathematics enrollments and number of graduates holding a degree in mathematics at our own large, North American Institution follows a similar disparate trend. Overall, undergraduate enrollment has increased nearly 500\% from 1957 to 2013, and from 1980 to 2013 the number of total undergraduate student credit hours taught by this large, Canadian University increased by $42 \%$. Meanwhile, the undergraduate student credit hours taught by the Department of Mathematics increased by over $120 \%$, while the number of Science, Technology, Engineering and Mathematics (STEM) degrees increased by less than $30 \%$, and the number of mathematics degrees remains extremely low, with a record high of 13 in 1985 and a low of 4 in 2013. The mathematics department, with one of the smallest budgets on campus, is now teaching over $5 \%$ of the total undergraduate credit hours at the university (with the Faculties of Science and Engineering teaching well over $25 \%$ of the total undergraduate credit hours), and mathematics undergraduate degrees account for less than $0.1 \%$ of all degrees conferred. This trend occurring at our university implies that the increase in credit hours taught by the mathematics department is attributed to the increase of students enrolling primarily in first-year math courses, including terminal courses, in order to meet the requirements of their degree.

A related trend, one better illustrating the limited persistence in undergraduate programs in which mathematics plays a significant part, is the decline of enrollment in mathematics courses above first year. In the 2014-2015 school year, the Department of Mathematics had 6340 students enrolled in first-year courses, 1859 in second year, 464 in third year, and just 32 in fourth, meaning that the department had 'filtered' out over $70 \%$ of its students each year. Although the numbers in first year and to some extent in second year represent service teaching to students in other programs, most students in first year at this university are registered as "University 1 " students and have not yet selected a major. With so many students coming through our classes in their first year of post-secondary study, it seems that we are not doing a very good job of attracting them to continue with the study of mathematics. As one particular illustration, we can compare undergraduate students in a large, non-STEM faculty such as the Faculty of Arts to 
those in the Faculty of Science. Whereas Arts has 4570 students registered in first-year courses, 1803 students in second year, and 1789 students in third year, Science has 4270 in first year, 2050 in second year, and only 1303 in third year (most of the degrees conferred in these two faculties are 3-year degrees). The sharp decline in students registered in second-year courses versus third-year courses (and thus being able to graduate with a 3-year degree) in Science is not seen in Arts, where there is very nearly the same number of students registered in second-year courses as that in third-year courses.

Success in mathematics courses may not only determine retention in STEM majors, but in overall university success, as there seems to be a correlation between timely completion of a 4-year degree and success in introductory mathematics courses [32]. Thus, although university enrollments are increasing and mathematics departments are teaching more students than ever, persistence within mathematics-based programs is not reflecting these developments, and mathematics continues to be a barrier for many postsecondary students.

What is happening in our first-year mathematics courses that is so effectively closing the door to further participation in mathematics courses, STEM fields, and post-secondary education as a whole?

Currently, failure and withdrawal (FDVW) rates in undergraduate mathematics courses across North America and internationally are disappointingly high, ranging anywhere from $30 \%$ to as high as $60 \%[1,11,17,19,37]$, and there are very low gradepoint averages for the students who do in fact manage to complete the courses [19]. This situation is reflected in the grade data collected from our own University. A Challenge of Numbers (1990) found that students with lower grade-point averages (GPAs) were less likely to continue with their freshmen choice of a mathematics major (pp. 38), and when the reality of the matter is that failure and withdrawal rates for first-year mathematics courses are near 50\% [19], it becomes clear to see why so many students are being 'filtered' out of mathematics majors and in fact all disciplines that require higher level mathematics courses (NRC [29], pp. 21). Rates this high re-enforce the outdated notion of mathematics as a gatekeeper-which "refers to the exclusion of students from further involvement in school mathematics, in school, and beyond, based on their lack of success as mathematics learners" [25]. As Derek Holton points out, "if mathematics is seen as a major that is harder to complete it may also be avoided in favour of easier subjects that have similar financial rewards" ([16], pp. 9). In institutions that require their students to complete a math course for graduation, rates as high as these mean that mathematics courses could be filtering approximately half of the undergraduate population out of further mathematics study, STEM degrees, and even post-secondary study altogether.

The trends discussed above describe the historical lack of participation and persistence in undergraduate mathematics, which is what we attempted to address with our strategy to re-think the structure of one of our own first-year mathematics courses.

\section{The course}

During the Fall and Winter terms of the 2014-2015 school year, the issues of high FDVW rates and low average GPAs were addressed by re-structuring the format of the terminal course MATH 1010: Applied Finite Mathematics. There were three sections 
during that school year, each containing 150, 150, and 240 students. Historically, this course has had extremely high FDVW rates, with the average over the last decade being nearly $49 \%$. Even more concerning was the fact that this number has been increasing in a statistically significant way (Cox-Stuart test for Trend, $p<0.05$ ), and grade-point average has also been quite low, hovering around a $\mathrm{C}+$ over the last decade.

The effect of attitude on mathematics success is well documented, and studies have shown that attitude is an important factor in achieving success in mathematics [23, 31]. A majority of the students in MATH 1010 are from faculties outside of the Faculty of Science, and for all but a small few of them, this will be their last encounter with mathematics at the post-secondary level. For these students, it is especially important that the effect of this course on their attitude toward learning mathematics be positive.

Another issue surrounding attitude toward mathematics is that approximately $10 \%$ of students who complete this course continue on to earn degrees from the Faculty of Education specializing in early and middle years teaching. Several authors have noted that mathematical anxieties can be passed down from teacher to student [2, 18, 27]; thus, it is crucial that we take the opportunity presented to us in this course to reverse any negative attitudes and mathematical anxieties from the past, and structure the course in such a way that all students are provided the opportunity for success and a positive experience in mathematics.

There has been a multitude of investigation into instructional practices of mathematics courses at the undergraduate level. Some of these include the use of technology to promote discovery and the use of multiple representations $[5,9,12,28]$, the use of discourse and methods such as scientific debate in the classroom [14, 22], and the inclusion of real-world applications and project-oriented problem solving to motivate theory ([10], vii, pp. 10, pp. 20; [15], pp. 65), as well as classroom techniques for large classes [20]. Although these practices certainly played parts (in varying degrees) in our MATH 1010 classroom, we chose to focus on addressing the possible effects that an alternate course structure could have on student success, rather than focusing on the effect of specific teaching strategies.

Mastery-based learning is an educational philosophy in which students achieve a desired grade demonstrating mastery of given content before moving to new content in a course. The idea of mastery-based learning has been observed in classrooms since the 1920s where students were required to demonstrate sufficient skills in an area assessed by a formative test before moving to new content. If the student was unable to achieve mastery of the content, tutoring or extra instruction was provided in order to help the student reach mastery (Kuilk et al. 1990). In a particular mastery-based approach called Bloom's Learning for Mastery (LFM), course content is teacher presented and divided into short units, and at the close of each unit, students complete a test in order to demonstrate mastery of the unit. Based on this model, Bloom [3] predicted that $90 \%$ of students would achieve grades in the top 10th percentile. Bloom [4] also states that weak students will not need more time to complete the tasks but generally only need more time to reach proficiency in beginning stages of a course [21]. In a paper by Kulik et al., [21] a meta-analysis was performed on mastery-based programs, and they concluded that in 12 of 14 studies that examined student attitude, students showed an increased positive attitude toward subject matter in mastery-based environments (1990). Other 
positive effects observed in mastery-based environments are that teachers feel more personal responsibility for students' learning, hold high expectations for their students and have a more positive attitude toward teaching [39].

Examples of the implementation of mastery-based learning can be seen in schools around the world. In Dryersburg High School in Tennessee, mastery-based learning was incorporated into Algebra I with great success. Students seemed to retain what they had learned, gained self-confidence by achieving grades of A or B, and improved the quality of their work [39]. In Kelana Jaya, Selangor, Malaysia, mastery learning was introduced in a discrete mathematics course for 30 students majoring in mathematics under a Bachelor of Education program at the University Tun Abdul Razak. Students were taught short units and provided a formative assessment at the end of each unit. If the student achieved the desired grade, they were moved to the next unit, and students who did not achieve mastery were permitted to repeat a unit until mastery (a grade of $80 \%$ or higher) was achieved. Students who were repeating a unit worked simultaneously on the new unit(s) as well. At the end of the study, students commented that they felt they had understood the material, felt mastery learning encouraged them to study independently and that the repetition helped increase retention [34].

The literature on the effects of class size on various factors such as student achievement, engagement, and satisfaction in mathematics is mixed. There are some researchers who find no significant effects of class size on these variables [7], others who find that effects can be negated by the use of technology in the classroom [13], and some others who claim that the effects of small class size in mathematics are most significant for females [30]. Still others highlight the differences in classroom practices that arise from the use of large class sizes in undergraduate education. Cuseo [8] notes that in classes with large enrollments, "there is an increased reliance on the lecture method of instruction" (pp. 2), leading to less active student involvement in the learning process and reduced frequency of instructor interaction and feedback to students. In terms of class size in conjuncture with mastery learning, smaller class sizes have also been shown to aid in the reduction of extra time needed to reach mastery of the material [21].

The course structure that we used as a model for our own was first implemented by C. Card and D. Siewert of the Black Hills State University in response to low success rates in their Basic Algebra course (2013). In this course structure, students were provided an early "alert" mechanism, which allowed them a second chance to learn and master the course outcomes, while still covering the same course content as in previous terms. With this course structure, the developers saw an improvement in pass rates from approximately $50 \%$ to approximately $80 \%$ [6]. However, this structure was developed in order to address students' lack of success in secondary mathematics courses. We wanted to see if a structure based on the model by C. Card and D. Siewert, with which they had much success, could offer the same opportunity for success in a large, tertiary level mathematics course by maximizing the effects of mastery learning in conjuncture with the positive effects of small class sizes. Although, due to resource limitations, it is in most cases not viable to simply reduce class sizes across the board, this course structure allows for targeted identification of students who would most benefit from a smaller class, and an opportunity for these students to benefit from the positive effects of a more active learning environment and more frequent instructor interaction in the classroom. 


\section{Methods}

Figure 1 depicts how we restructured MATH 1010, which was broken into two tracks (A and B) and three content blocks (Units 1, 2, and 3).

All students began the course together with the Track $A$ instructor, and after 3 weeks, all wrote the first unit test. Students who achieved less than $55 \%$ on the first unit test were alerted with an email that they would now be attending the Track $B$ class. Track $B$ was scheduled at the same time but in a different room with a different instructor. Students were also permitted to opt into Track $B$ following a unit test if they achieved greater than $55 \%$, but were dissatisfied with their grade. Once a student was moved into Track $B$, due to a failing grade or opting in, there was no movement back to Track $A$. Students who failed to meet the outcomes the first time were given the opportunity to repeat the content on which they did not achieve mastery in an environment with a smaller class size, allowing for more active and student-centered classroom instruction, more interaction and frequent feedback from the instructor, and scaffolding of content.

For the following 3-week block, the two tracks ran simultaneously, with students in Track $A$ moving on to the second unit, while students in Track $B$ had the opportunity to engage with the Unit 1 material once again, in a smaller class setting. At the close of this 3 week period, Track $A$ students wrote a test for Unit 2, while Track $B$ students wrote a second Unit 1 test covering the same content as their first attempt but with different questions. Students in Track $A$ passing for the second time moved on to the third unit in Track $A$, while those who did not achieve the passing score (or who were not happy with

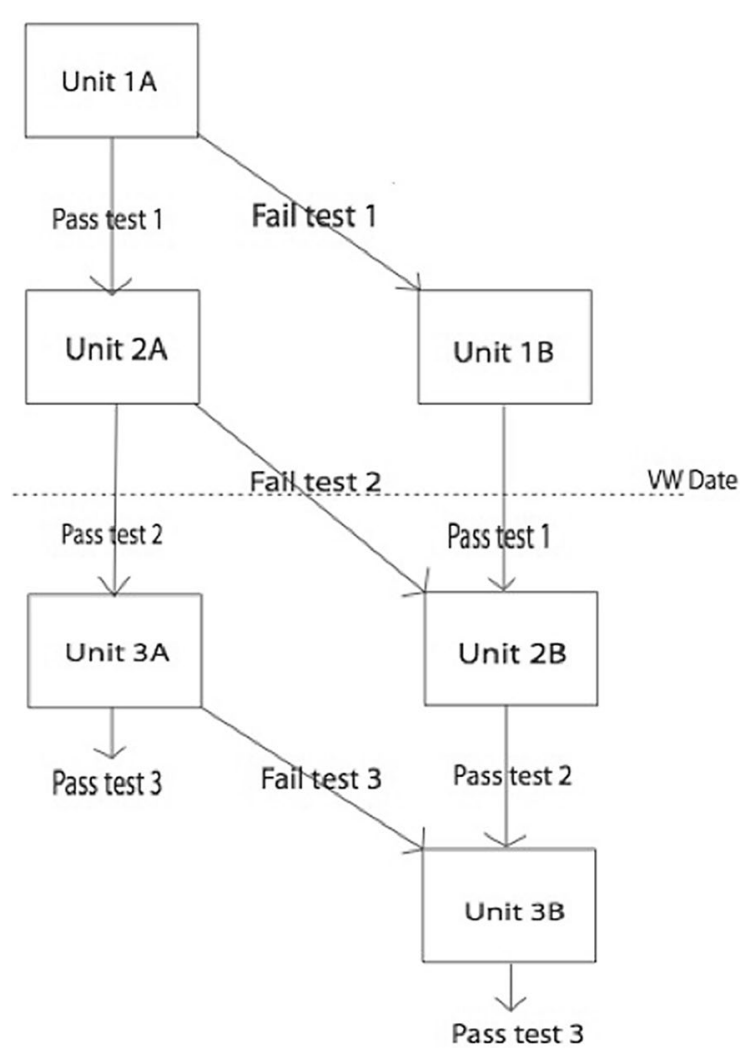

Fig. 1 MATH 1010 new course structure 
their score) moved into Track $B$. Those in Track $B$ who passed moved on to the second unit; however, those who failed any unit test for the second time while in Track $B$ were informed that they did not satisfy the requirement of the course to successfully pass all three unit tests, and thus would not be eligible to receive a passing grade in the course. Students had the option of voluntarily withdrawing from the course had they received a failing grade on the Unit 1 or 2 tests while in Track $B$.

The next 3-week block ran through the third Unit of content for those in Track $A$, and the second Unit for those in Track $B$. Students successfully completing all three Unit tests in Track $A$ finished the course 2 weeks early, while those who had moved into Track $B$ throughout the term finished at the usual time. Both of the third Unit tests in Track $A$ and $B$ were written after the voluntary withdrawal date.

In the past, the assessment criteria of the course consisted of two term tests (multiple choice only), cumulative final exam (multiple choice and long answer), and four or five handwritten assignments. In the new structure, assessment and evaluation were based on three noncumulative term tests, consisting of multiple choice and long-answer questions and 10 online assignments. Although the tests were specifically noncumulative, the nature of the content covered from unit to unit did require transfer of knowledge from previous units, and the tests were comparable in difficulty and length to those of the previous years. We felt that this format for the tests was appropriate for this course structure because of the structure of the assessment and evaluation. Students were required to achieve 55\% or higher on all three of the term tests in order to achieve a passing grade in the course. Although 55\% may seem low for mastery-based learning, we were required by the faculty to set the passing grade below $60 \%$ during this trial course structure. In the past, a passing grade for Math 1010 has been as low as 46\%, and students could achieve much less than this on any one examination, only to make it up on a later examination. In the previous course structure, students could fail one or two of the term tests and still end up in achieving a passing grade in the course. Thus, although "mastery" typically represents a higher level of achievement than $55 \%$, in our context where historically students were completing the course having "mastered" less than half of the course content, our operational definition of mastery was to have mastered over half of the content from every single unit. We felt that this represented a significant level of familiarity with the material covered, and this is what we required in order to pass the course.

\section{Results and discussion}

The results of our implementation of a revised course structure went well beyond our own expectations, both in terms of the relevant statistical outcomes as well as more qualitative measures of success.

Figures 2 and 3 show the changes in FDVW rates and grade-point averages that resulted from the new course structure.

The FDVW rate dropped significantly, from an average over the past 5 years of 48.8, to $15.9 \%$ in the 2014-2015 year, whereas the average GPA increased significantly, from an average over the past 5 years of 2.29 , to 3.60 (on a 4.5 scale). This is even more significant when taking into account the fact that the grade cut-offs used for this term, based on the structure of the course, were higher than ever before (see Table 1). 
Barr and Wessel Fields Math Educ J (2018) 3:3

Page 8 of 13

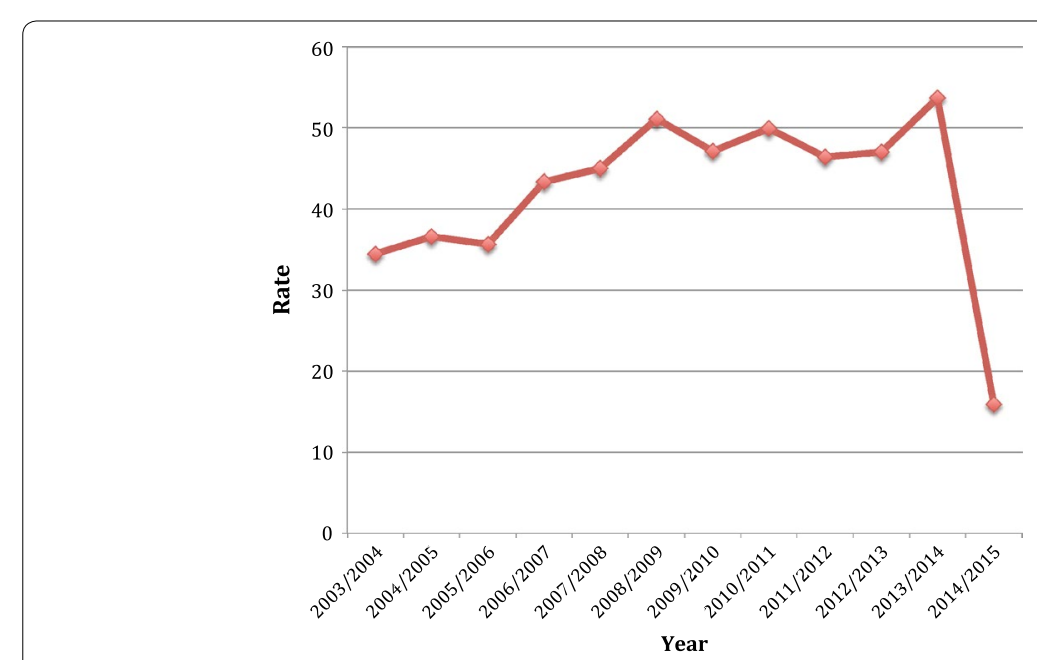

Fig. 2 Historical FDVW rates

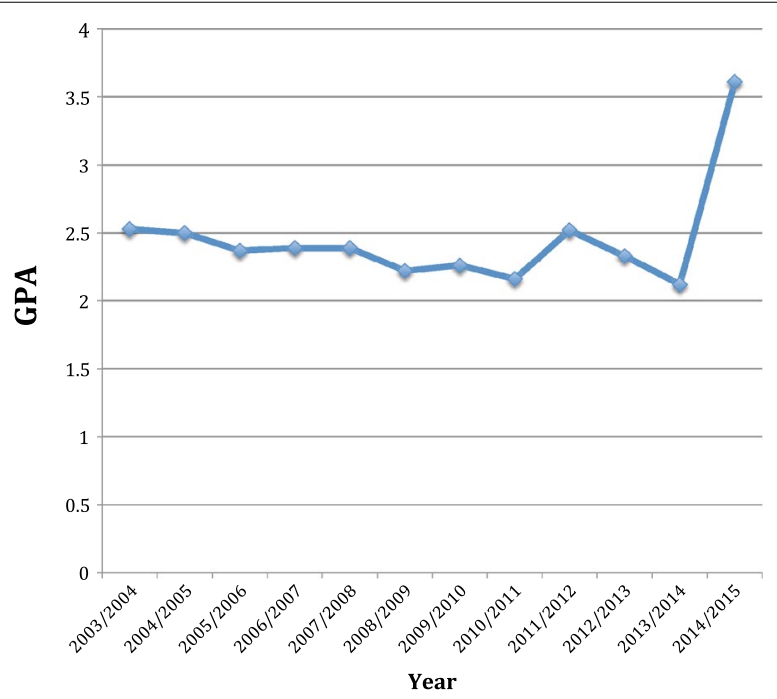

Fig. 3 Historical average GPA rates

Table 1 Grade cutoffs

\begin{tabular}{ll}
\hline A+ & $95-100$ \\
A & $85-95$ \\
B+ & $78-84$ \\
B & $72-77$ \\
C & $67-71$ \\
C & $61-66$ \\
D & $55-60$ \\
F & $0-55$ \\
\hline
\end{tabular}


In order to test for significance of these results, grade data for all students from the 2013/2014 year (which is representative of the average GPA of the past 5 years) were compared to data for the 2014/2015 year using an independent samples $t$ test, which showed a significant difference in the average GPAs between the two sample years $(p<0.001)$. Thus, the course restructure had a statistically significant effect on average GPA.

Furthermore, a regression analysis was done to analyze the relationship between the two variables: FDVW rate and average GPA. This analysis shows that there is a linear relationship between FDVW rate and average GPA for the years before 2014/2015 that can be described by the equation GPA $=3.11-0.0172$ FDVW. Given that the FDVW rate was $15.9 \%$ in the $2014 / 2015$ year, the equation would predict the average GPA to be 2.83 . However, in actuality, it was 3.6, so that difference (residual) is +0.77 increase in grade point from what would be expected. Including the FDVW rate for the last year into the original model, the equation of the line would change to GPA $=3.898-0.0343$ FDVW. Using this equation gives a predicted GPA of 3.35, which still yields a positive result of 0.245 average grade points. Thus, not only are the FDVW rates and average GPAs higher than ever before, but even with the given FDVW rate, the GPA is significantly higher than that could be predicted by linear regression.

Although the 55\% mastery level may have been an appropriate initial cut-off, it demonstrated that the students understood enough of the content in that particular unit and were able to continue through the course. At the conclusion of the trial, only $0.5 \%$ students received overall grades between 55 and $66 \%$ in the course. In the end, $90 \%$ of students achieved grades of B or higher in the course. In the past, this fluctuated greatly from about 30 to $60 \%$ of students attaining such success. Also, in the mastery-based environment in both tracks, students generally had an increased positive attitude toward mathematics, a subject in which many of them had struggled in the past and tended to work harder to achieve their desired grade. These results can be seen in more detail in the student survey section.

In addition, a survey was administered at the end of each term, asking the students to respond to the following open-answered questions:

1. What, if anything, did you learn about LEARNING mathematics from this course?

Overwhelmingly, the responses to this question from the students in both tracks indicated they learned that practice and working through problems was crucial to success in learning mathematics, and that mathematics can be useful in the real world.

Other responses included specifics about study habits and time management, opinions that math can be enjoyable and is not as hard as it seems, and that teaching style has an effect on learning mathematics.

2. Did the knowledge that you may be able to/have to move into Track B cause you to work differently in the course than you may have otherwise? (i.e., less hard or more hard?). Elaborate

We chose to ask this question because initially, we were concerned that students might be more lackadaisical in their efforts knowing they had Track $B$ as a "safety 
net." This did not seem to be the case, as in the end, many students from Track $A$ felt motivated to work harder in order to remain in Track $A$ and complete the course 2 weeks prior to the end of term. In Track $B$, the response of working harder was also the most popular, but a large proportion of those students indicated that they worked even harder once they were moved into Track $B$.

Other popular responses discussed the fact that knowing that there was a "second chance" or "backup plan" led to less stress and anxiety. To a smaller scale were the responses that their work ethic was not affected by the new course structure at all, and less than $2 \%$ of students indicated that the new structure made them work less hard.

3. Any general comments on the track $A / B$ system?

Almost all of the students (all but 2) had positive comments about the new course structure. Many made statements about the comforting nature of knowing that a second chance was available, and that the early finish was a good motivator.

The students in Track $A$ wrote about liking the opportunity to opt into Track $B$ to possibly improve their grades, while those in Track $B$ wrote about how it was an opportunity for a second chance to make up for a failing grade. Those students also made comments about the smaller class size, slower pace, and more intimate and interactive nature of the Track $B$ classroom.

The students in Track $B$ were asked the additional question:

4. Have your study/work habits changed since moving into Track B?

The majority of the students who responded to this question indicated that they worked harder and did more practice upon moving into Track $B$, while some stated that their work ethic remained the same. They also commented on feeling more comfortable seeking help, being more involved in class, more focused, understanding more, knowing that this was their last chance to pass the course, and the positive aspects of a slower pace and smaller class size.

When all was said and done, more than $70 \%$ of the students who failed a unit test and were moved into Track $B$ were able to successfully pass the course in the end, achieving mastery on all three units (a graph of students progressing through each track can be found in Fig. 4 and Table 2). These were students who were struggling in the course and who historically would have accounted for the population of high FDVW rates. It was also clear from these open-ended survey responses that the attitudes of the students completing the course were quite positive regarding their experiences, which would certainly be different from the attitudes of the nearly $50 \%$ of students who were failing or withdrawing from the course in previous years. 

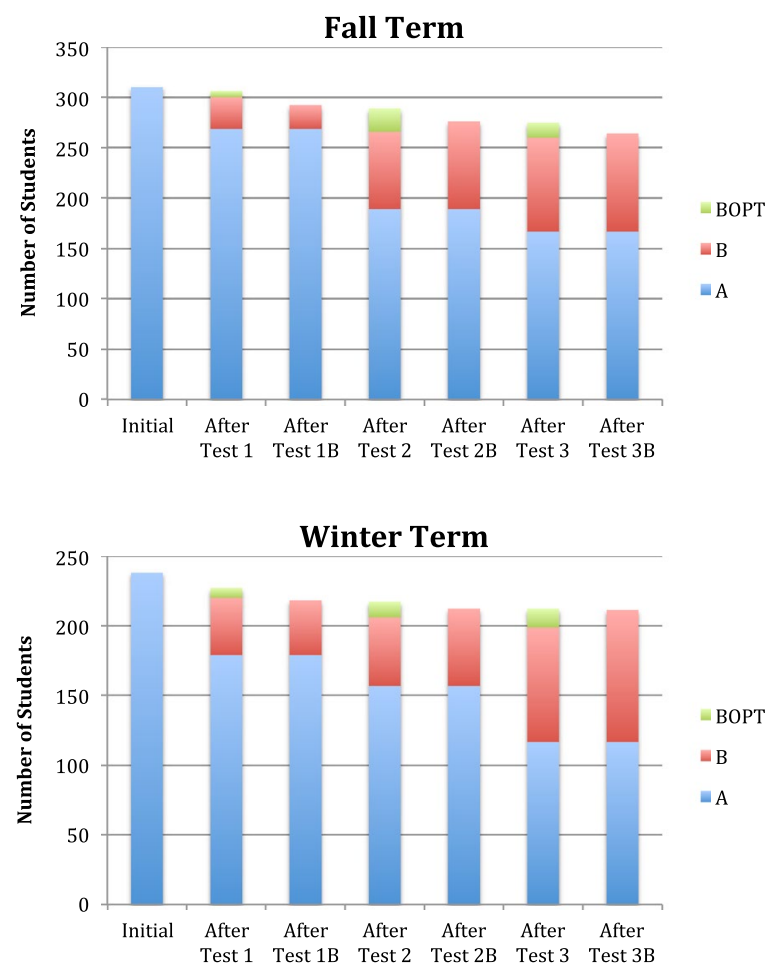

Fig. 4 Students in each track

Table 2 Distribution of students between tracks and terms

\begin{tabular}{lllll}
\hline & B & B OPT & A & Total \\
\hline Fall & 80 & 39 & 171 & 290 \\
Winter & 74 & 30 & 119 & 223 \\
\hline
\end{tabular}

$B$ Opt indicates students who opted into Track $B$ after any unit test

\section{Conclusions}

We were extremely encouraged by the results of our trial with this course structure. It is clear that the experience of students in first-year mathematics courses can shift from one of anxiety and failure to opportunity and success by combining mastery learning strategies with the beneficial features of small class sizes for students who are struggling the most. By changing the structure of a course to allow for early alerts and second chances, we can open the door to undergraduate mathematics and beyond.

As instructors for the course over the 2014-2015 school year, we experienced changes in the dynamics of our classrooms. As the course went on, Track $A$ became more and more streamlined. The students remaining in the this classroom were more homogeneous, and thus the class was able to progress at a quicker pace, with less time needed to slow down or repeat explanations. There was more discussion in the group, and more opportunity to ask challenging questions as well as explore more difficult and interesting examples.

Due to the smaller class size, Track $B$ allowed for more one-on-one attention from the instructor as well as group work and class discussions. At times, students were able 
to work on in-class problems individually or with a classmate, while the instructor circulated the room assisting students as needed. More time was allotted for questions from students, as well as detailed explanations. Track $B$ also provided students with a second opportunity to master the course content, which allowed for proper scaffolding leading to mastery of material. What transpired in Track $B$ was more than simply a result of a smaller class size. Rather, this was a targeted reduction of class size for those students who were identified through the tests as needing additional intervention and remediation.

By allowing for an early "alert" mechanism to identify those students who need further assistance (both to the instructors of the course and to the students themselves), students had a second chance to address the content in a new environment, and to rethink and re-experience their approaches to learning mathematics while still having the opportunity to complete the course without outside remediation or a delay in their program.

As an extension of this project, we would like to encourage instructors of other departments that experience similar high FDVW and low GPA results to experiment with course structure, as we feel that our results have implications reaching farther than mathematics courses. In the future, we plan on tracking the students from our cohort to compare their attrition rates (from mathematics courses, STEM disciplines, and university as a whole) to statistical data about overall attrition rates at our institution.

\section{Authors' contributions}

DB applied for funding grant and developed and coordinated the implementation of the project. DB and LW both participated in the teaching of the course (all 3 sections) under the new course structure. DB compiled and analyzed the historical and new data. Both authors contributed to the writing of the manuscript. Both authors read and approved the final manuscript.

\section{Acknowledgements}

The authors would like to thank the Faculty of Science and Department of Mathematics at the University of Manitoba, Carrie Paquette from the Department of Statistics at the University of Manitoba, as well as the Teaching and Learning Enhancement Fund and the Centre for the Advancement of Teaching and Learning's Innovation Projects Grant for their support.

\section{Competing interests}

The authors declare that they have no competing interests.

\section{Publisher's Note}

Springer Nature remains neutral with regard to jurisdictional claims in published maps and institutional affiliations.

Received: 24 February 2016 Accepted: 13 October 2017

Published online: 08 December 2017

References

1. Ahlgren-Reddy, A., Harper, M.: Mathematics placement at the University of Illinois. Probl. Resour. Issues Math. Undergrad. Stud. 23(8), 683-702 (2013)

2. Beilock, S., Gunderson, E., Ramirez, G., Levine, S.: Female teachers' math anxiety affects girls' mathematics achievement. Proc. Natl. Acad. Sci. USA. 107, 1860-1863 (2010)

3. Bloom B.S.: Master learning. In: Evaluation comment 1(2). University of California in Los Angeles, Center for the Study of Evaluation of Instructional Programs, Los Angeles (1968)

4. Bloom, B.S.: Human characteristics and school learning. McGraw-Hill, New York (1976)

5. Campe, K.D.: Do it right: strategies for implementing technology. Math. Teach. 104(8), 620-625 (2011)

6. Card, C., Siewert, D.: Developmental math as a gateway, not a gatekeeper. Mathfest [Conference], Hartford (2013)

7. Cheng, D.A.: Effects of class size on alternative educational outcomes across disciplines. Econ. Educ. Rev. 30(2011), 980-990 (2011)

8. Cuseo, J.: The empirical case against large class size: adverse effects on the teaching, learning, and retention of firstyear students. J. Fac. Dev. 22(1), 5-21 (2007) 
9. DePeau, E.A., Kalder, R.S.: Using dynamic technology to present concepts through multiple representations. Math. Teach. 104(4), 268-273 (2010)

10. Dossey, J.A. (ed.): Confronting the core curriculum: Considering change in the undergraduate mathematics major: Conference proceedings. Math Association of America, Washington, DC (1998)

11. Eng, T.H., Li, L.V., Julaihi, N.H.: Lecturers' perceptions, students' problems and solutions for handling high-failure rate mathematics courses. Proc. Soc. Behav. Sci. 90, 853-861 (2013)

12. Fonger, N.L.: Equivalent expressions using CAS and paper-and-pencil techniques. Math. Teach. 107(9), 688-693 (2014)

13. Gleason, J.: Using technology-assisted instruction and assessment to reduce the effect of class size on student outcomes in undergraduate mathematics courses. Coll. Teach. 60(3), 87-94 (2012)

14. González-Martín, A.S., Bloch, I., Durand-Guerrier, V., Maschietto, M.: Didactic situations and didactical engineering in university mathematics: cases from the study of calculus and proof. Res. Math. Educ. 16(2), 117 (2014)

15. Hillel, J.:Trends in curriculum: a working group report. In: Holton, D. (ed.) The teaching and learning of mathematics at university level: an ICMI study, pp. 59-70. Kluwer Academic Publishers, Dordrecht (2001)

16. Holton, D., Muller, E., Oikkonen, J., Valenzuela, O.A., Zizhao, R.: Some reasons for change in undergraduate mathematics enrolments. Int. J. Math. Edu. Sci. Tech. 40(1), 3-15 (2009)

17. Hourigan, M., O'Donaghue, J.: Mathematical under-preparedness: the influence of the pre-tertiary mathematics experience on students' ability to make a successful transition to tertiary level mathematics courses in Ireland. Int. J. Math. Edu. Sci. Tech. 38(4), 461-476 (2007)

18. Jackson, E.: Mathematics anxiety in student teachers. Pract. Res. High Educ. 2(1), 36-42 (2008)

19. Kalajdzievska, D.:Towards university readiness. The art and science of mathematics education [Conference]. University of Winnipeg, Winnipeg (2011)

20. Kalajdzievska, D.: Taking math students from 'blah' to 'aha': what can we do? Prob. Resour. Issues Math. Undergr. Stud. 24(5), 375-391 (2014)

21. Kulik, C., Kulik, J., Bangert-Drowns, R.: Effectiveness of mastery learning programs: a meta-analysis. Rev. Educ. Res. 60(2), 265-299 (1990)

22. Legrand, M.: Scientific debate in mathematics courses. In: Holton, D. (ed.) The teaching and learning of mathematics at university level: an ICMI study, pp. 127-136. Kluwer Academic Publishers, Dordrecht (2001)

23. Ma, X., Kishor, N.: Assessing the relationship between attitude toward mathematics and achievement in mathematics: a meta-analysis. J. Res. Math. Educ. 28(1), 26-47 (1997)

24. Madison, B.L., Hart, T.A.: A challenge of numbers: people in the mathematical sciences. National Academy Press, Washington, DC (1990)

25. Mason, R.T: A kinder mathematics for Nunavut. In: Kanu, Y. (ed.) Curriculum as cultural practice: postcolonial imaginations, pp. 131-148. University of Toronto Press Incorporated, Toronto (2006)

26. Mattern, K.,D., Packman, S.: Predictive validity of Accuplacer scores for course placement: a meta-analysis. College Board Research Report \#2009-2. https://research.collegeboard.org/publications/content/2012/05/predictive-validity-accuplacer-scores-course-placement-meta-analysis (2009). Accessed 29 Dec 2014

27. McAnallen, R.: Examining mathematics anxiety on elementary classroom teachers; Doctoral dissertation; University of Connecticut. J. Educ. Inf. Stud. 6(2), 4 (2010)

28. Nabb, K.: Students' exploratory thinking about a nonroutine calculus task. Math. Teach. 106(6), 432-439 (2013)

29. National Research Council: Moving beyond myths: revitalizing undergraduate mathematics. National Academy Press, Washington, DC (1991)

30. Nye, B., Hedges, L.V., Konstantopoulos, S.: Do minorities experience larger lasting benefits from small classes? J Educ Res 98 (2), 94-100 (2004)

31. Pan-Canadian Assessment Program (PCAP). Council of Ministers of Education, Canada (2010)

32. Parker, M.: Placement, retention, and success: a longitudinal study of mathematics and retention. J. Gen. Educ. 54(1), 22-40 (2005)

33. Rylands, L.J., Coady, C.: Performance of students with weak mathematics in first-year mathematics and science. Int. J. Math. Educ. Sci. Technol. 40(6), 741-753 (2009)

34. Shafie, N., Shahdan, T.N.T., Liew, M.S.: Mastery learning assessment model (MLAM) in teaching and learning mathematics. Proc. Soc. Behav. Sci. 8, 294-298 (2010)

35. Steen, L., A.: Calculus today. In: Proceedings from the conference of the Mathematical Association of America: calculus for a New Century: a pump, not a filter. MAA, Washington, DC. pp. 12-14, 24-27 (1987)

36. Steen, L.A.: Revolution by stealth: redefining university mathematics. In: Holton, D. (ed.) The teaching and learning of mathematics at university level: an ICMI study, pp. 303-312. Kluwer Academic Publishers, Dordrecht (2001)

37. Stevenson, K., Zweier, L.: Creating a learning flow: a hybrid course model for high-failure-rate math classes. Educase Q. 34(4), n4 (2011)

38. Zevenbergen R (2001) Changing contexts in tertiary mathematics: implications for diversity and equity. In: Holton $D$ (ed). The teaching and learning of mathematics at university level: an ICMI study. Kluwer Academic Publishers, Dordrecht. pp. 13-26

39. Zimmerman, B., DiBenedetto, M.: Mastery learning and assessment: implications for students and teachers in an era of high-stakes testing. Psychol. Sch. 45(3), 206-216 (2008) 